\title{
Changes of chemical properties and the water vapour sorption of Eucalyptus pellita wood thermally modified in vacuum
}

\author{
Bailing Sun ${ }^{1} \cdot$ Zhe Wang $^{1} \cdot$ Junliang Liu ${ }^{1}$
}

Received: 15 August 2016/ Accepted: 14 November 2016/Published online: 8 February 2017

(C) The Japan Wood Research Society 2017

\begin{abstract}
The aim of this study was to evaluate the chemical composition and the dynamic water vapour sorption properties of Eucalyptus pellita wood thermally modified in vacuum. For this purpose, wood samples were thermally modified in a vacuum oven at $160-240{ }^{\circ} \mathrm{C}$ for $4 \mathrm{~h}$. Chemical composition were investigated by wet chemical analysis, elemental analysis, as well as Fourier transform infrared (FTIR) analysis, and dynamic water vapour sorption properties were evaluated by dynamic vapour sorption apparatus. The results showed that holocellulose and alpha-cellulose contents decreased and lignin and extractives contents relatively increased during the heat process. Elemental analysis showed a reduction in hydrogen content and an increase in carbon content. FTIR analysis indicated that the degradation of hemicellulose and condensation reactions of lignin occurred. In addition, the thermo-vacuum resulted in a reduction in the equilibrium moisture content of wood during the adsorption or desorption process. And the sorption hysteresis had a decreasing trend with increasing treatment temperature. The development of the hygroscopicity was related to the increase in the relative content of lignin, the degradation of the carbonyl groups in xylan and the loss of carbonyl group linked to the aromatic skeleton in lignin after heat treatment.
\end{abstract}

Keywords Eucalyptus pellita - Thermo-vacuum treatment $\cdot$ Chemical changes - Dynamic water vapour sorption

Junliang Liu

liujunliang@caf.ac.cn

1 Research Institute of Wood Industry, Chinese Academy of Forestry, Haidian District, Beijing 100091, China

\section{Introduction}

In China, plantation forestry has played an important role in the supply of raw material to the wood industry. Eucalyptus is one of the most important plantation tree species in China. Eucalyptus wood has a number of desirable properties, including its attractive color, high density, strength, and hardness [1]. However, it has a strong dimensional instability, which is a limitation for its utilization. Heat treatment has been known as a process enhancing wood properties by reducing moisture absorption, improving dimensional stability and biological durability [2-5].

Wood is mainly composed of cellulose, hemicellulose, lignin, and extractives. The changes of wood properties are related to its chemical composition. The extent of the change of wood chemical properties depends on the type of the heat-treatment process, temperature, time, wood species as well as its initial moisture content. The chemical changes of wood during heat treatment have been evaluated through wet chemical analysis, Fourier transform infrared (FTIR) spectroscopy, elemental composition, nuclear magnetic resonance (NMR) [5-8]. Several studies indicated that heat treatment led to a relative increase in the contents of lignin and extractives, and a decrease in the content of holocellulose [9-12]. The increase in carbon content has been observed for black locust and beech wood by elemental analysis during heat treatment $[13,14]$. In addition, FTIR has been applied to track the chemical changes of wood before and after heat treatment. Those studies revealed that heat treatment resulted in the formation of condensation products, low-molecular-weight phenolic substances and oxidation products, as well as the reduction of acetyl groups, fats, waxes, and resin acids [15-17]. 
In recent years, the thermo-vacuum modification of wood has been developed as a new method to decrease the effects of oxygen on the loss of mechanical properties during heat treatment $[18,19]$. It has been found that the thermo-vacuum modification can also improve the dimensional stability of wood $[1,20]$. Up to date, several observations have been reported on the physical and mechanical properties of heat-treated wood in vacuum [21-23]. However, no results have been reported on the dynamic vapour sorption properties of thermo-vacuum treated wood. Therefore, the aim of this study was to investigate the effect of thermo-vacuum treatment on the chemical changes and dynamic water vapour sorption properties of Eucalyptus pellita wood to better understand sorption behavior of thermo-vacuum treated wood.

\section{Materials and methods}

\section{Wood samples and thermo-vacuum treatment protocols}

Eucalyptus pellita F. Muell. was obtained from China Eucalypt Research Centre in Guangdong Province, China. Eucalypt wood blocks of size $330 \mathrm{~mm} \times 40 \mathrm{~mm}$ $\times 40 \mathrm{~mm}(\mathrm{~L} \times \mathrm{T} \times \mathrm{R})$ were prepared from defect-free wood and air-dried. The samples were oven-dried at $(103 \pm 2){ }^{\circ} \mathrm{C}$ until a constant weight before thermo-vacuum treatment. Thermo-vacuum treatment was performed at $160,180,200,220$, and $240{ }^{\circ} \mathrm{C}$ for $4 \mathrm{~h}$ under the negative pressure $(-0.02$ to $-0.08 \mathrm{MPa})$, as described in Sun et al. [1]. The untreated wood blocks were used as control samples.

\section{Wet chemical analysis of wood components}

Wet chemical analyses of wood components have been performed on untreated and heat-treated E. pellita wood. Before chemical analysis, the wood samples were grinded, sieved $(0.425-0.250 \mathrm{~mm})$, and air-dried. The moisture content (MC) of the samples was determined by oven drying at $105{ }^{\circ} \mathrm{C}$ to a constant weight and the ash content was determined by ashing in a muffle furnace at $575 \pm 25^{\circ} \mathrm{C}$ for $6 \mathrm{~h}$ based on National Standard of the People's Republic of China [24, 25]. The contents of Klason lignin, holocellulose, alpha-cellulose in holocellulose, alcohol-benzene solubility, and $1 \% \mathrm{NaOH}$ extractives in E. pellita wood were determined according to National Standard of the People's Republic of China [26-30], which were described by Sun et al. [31]. The amount of each chemical component is reported as \% based on ash-free dry organic matter. Chemical analyses were performed in duplicate.

\section{Elemental analysis}

The analyses in the carbon and hydrogen contents were performed on a CHNOS Elemental Analyzer (vario EL III, Elementar Analysensysteme GmbH, Germany). Before analysis, the untreated and heat-treated $E$. pellita wood were grinded $(\geq 0.075 \mathrm{~mm})$ and oven-dried to a constant weight.

\section{FTIR analysis}

FTIR spectra were collected with a spectrometer Spectrum GX FTIR (Perkin-Elmer Inc., USA), equipped with a deuterated triglycine sulfate (DTGS) detector. Each spectrum was recorded in the region of $4000-400 \mathrm{~cm}^{-1}$ by an average of 32 scans at a resolution of $4 \mathrm{~cm}^{-1}$. The samples were chopped into small sticks, grinded, and sieved $(0.150-0.124 \mathrm{~mm})$. Then it was blended with $\mathrm{KBr}$ and compressed at a pressure of $8.5 \mathrm{t} \mathrm{cm}^{-2}$ to prepare a tablet. Three spectra were taken from each sample and the presented FTIR spectra were average value spectra.

\section{Dynamic water vapour sorption analysis}

The moisture sorption characteristics of the untreated and heat-treated wood samples were determined on microspecimens of approximately $5 \mathrm{mg}$ in the range of relative humidity (RH) between 0 and $95 \%$ at $25 \pm 0.1{ }^{\circ} \mathrm{C}$ using a dynamic vapour sorption (DVS) apparatus (IGAsorp, Hiden Isochema Ltd., UK). The weight changes of the wood samples were determined by an electronic microbalance with an accuracy of $0.1 \mu \mathrm{g}$. The instrument maintained a constant target $\mathrm{RH}$ until the mass change in the sample $(\mathrm{d} m / \mathrm{d} t)$ was less than $0.002 \%$ per minute over a $600 \mathrm{~s}$ period. The mass change was related to the dry weight of the sample.

\section{Results and discussion}

\section{Wet chemical analysis of wood components}

The changes in chemical composition of E. pellita wood before and after heat treatment are presented in Table 1. The chemical analyses revealed that during the thermovacuum treatment, the proportion of lignin and extractives increased, whereas the relative contents of holocellulose and alpha-cellulose decreased. Similar results have been reported by previous studies [8, 32-34].

The decrease in holocellulose contents can be mainly due to the reduction of hemicelluloses (polyoses) contents [35]. In general, hemicelluloses are less thermally stable than other wood constituents owing to their low 
Table 1 Chemical analysis of the wood components of untreated and heat-treated eucalypt wood

\begin{tabular}{lrrrrrr}
\hline Composition & Untreated & \multicolumn{7}{l}{ Heat treat temperature $\left({ }^{\circ} \mathrm{C}\right)$} \\
\cline { 3 - 7 } & & \multicolumn{1}{c}{160} & 180 & 200 & 220 & 240 \\
\hline Klason lignin* (\%) & 30.88 & 32.29 & 32.39 & 32.53 & 33.45 & 35.30 \\
Holocelllulose* (\%) & 74.25 & 68.17 & 65.68 & 62.17 & 56.17 & 47.06 \\
Alpha-cellulose in holocellulose* (\%) & 45.42 & 41.83 & 40.76 & 39.02 & 33.97 & 23.11 \\
Alcohol-benzene solubility* (\%) & 1.59 & 1.93 & 1.98 & 2.08 & 2.79 & 3.94 \\
1\% NaOH solubility* (\%) & 13.14 & 18.02 & 17.72 & 17.30 & 16.68 & 15.76 \\
\hline
\end{tabular}

* Thermo-vacuum treatment was performed for $4 \mathrm{~h}$ under the negative pressure $(-0.02$ to $-0.08 \mathrm{MPa})$ molecular weight, amorphous and branched structure. According to previous studies [36, 37], the degradation of hemicelluloses begins with deacetylation, followed by depolymerization catalysed by the released acetic acid. This leads to the reduction in polyoses contents. Cellulose is more stable than hemicelluloses because of its crystalline nature and is therefore affected less by heat treatment [38].

Lignin is considered as the most thermally stable constituent in the three main chemical components of wood. Previous results indicated that when the treatment temperature was $600{ }^{\circ} \mathrm{C}$, the mass losses of hemicelluloses were over $95 \%$, and those of cellulose were more than $80 \%$, whereas the mass losses of lignin were under $60 \%$ [39]. In this study, the relative content of lignin increased as the treatment temperature rose. This does not mean that there is an increase in the amount of lignin but the reduction in polysaccharides is higher. In addition, the condensation reactions might also lead to an increase of the lignin proportion [40, 41].

The content of alcohol-benzene extractives increased gradually as the treatment temperature rose. This is probably caused by the degradation of polysaccharides during heat treatment [42]. The content of $1 \% \mathrm{NaOH}$ extractives increased at low treatment temperature, reaching a maximum value at $160{ }^{\circ} \mathrm{C}$. After that, the relative content of extractives decreased. Similar results have been reported for heat-treated pine and eucalypt wood [10, 41]. This trend may be due to the appearance of new extractable compounds resulting from polysaccharide degradation at $160{ }^{\circ} \mathrm{C}$. As the treatment temperature increases further, new compounds degrade to volatiles that leave the wood, resulting in a decrease in the extractives content.

\section{Elemental analysis}

Chemical structure modifications can result in the elemental changes of the molecules. The relative contents of carbon and hydrogen before and after thermo-vacuum treatment are shown in Fig. 1. As shown in Fig. 1, there was a decrease in the content of hydrogen, whereas the carbon content had an increasing trend as

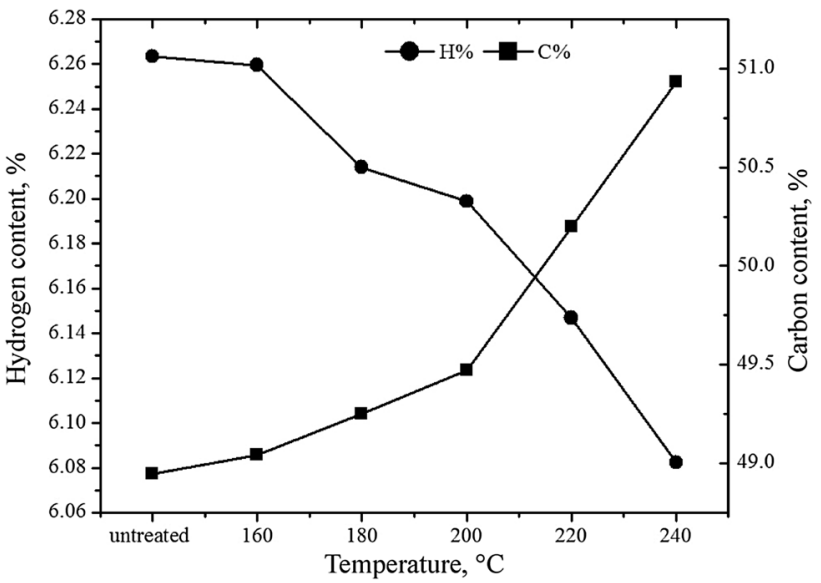

Fig. 1 Carbon and hydrogen contents of untreated and heat-treated eucalypt wood

the treatment temperature rose. Therefore, the ratios of $\mathrm{H} / \mathrm{C}$ decreased with the increase of treatment temperature, which might be due to the elimination of water caused by dehydration of the carbohydrates [43, 44]. During heat treatment, carbonic acids are formed as a result of cleavage of the acetyl groups in polyoses. In the meantime, polyoses are hydrolyzed into oligomeric and monomeric structures. Subsequently, the monomeric structures are dehydrated to aldehydes [36, 37]. Such reactions could also contribute to a further decrease of hydrogen content.

\section{FTIR analysis}

The FTIR spectra of untreated and heat-treated E. pellita wood are shown in Figs. 2 and 3. The bands in the $3800-2750 \mathrm{~cm}^{-1}$ region are assigned to the hydroxyl and methyl/methylene stretching vibrations. As shown in Fig. 2, a broad band with a maximum at $3420 \mathrm{~cm}^{-1}$ was observed. This band shifted to lower wavenumbers with the increase of treatment temperature. According to previous studies [45, 46], the broadening of the $\mathrm{OH}$ band is considered as a result of a mixture of intermolecular and intramolecular hydrogen bonds. 


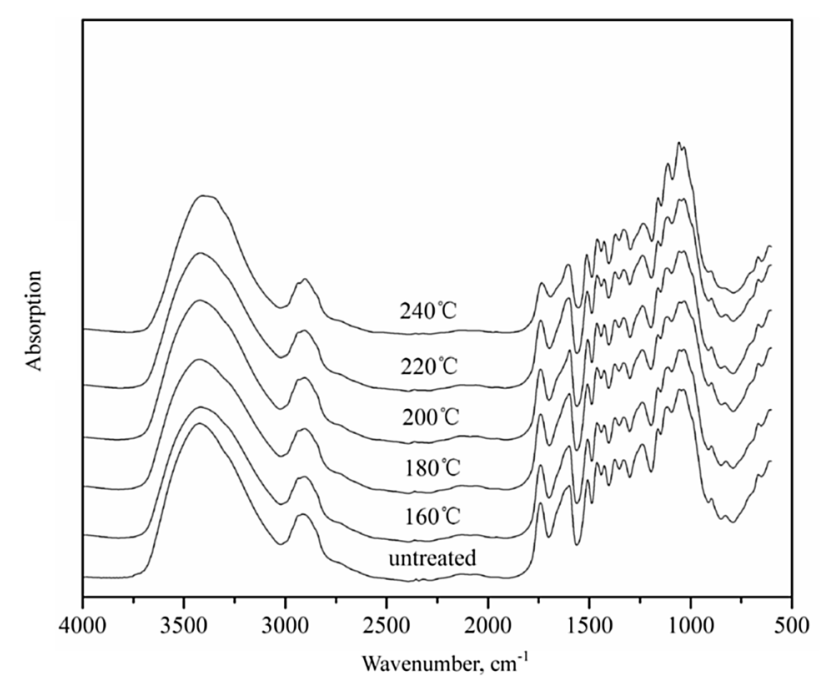

Fig. 2 FTIR spectra of untreated and heat-treated eucalypt wood (4000-600 $\mathrm{cm}^{-1}$ )

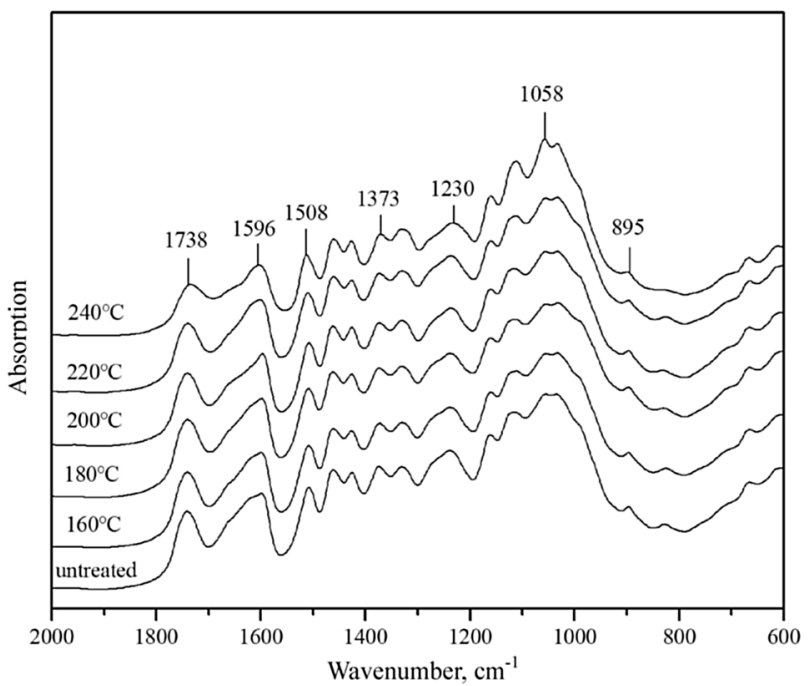

Fig. 3 FTIR spectra of untreated and heat-treated eucalypt wood (2000-600 $\left.\mathrm{cm}^{-1}\right)$

The "fingerprint" region $2000-600 \mathrm{~cm}^{-1}$ is mainly analyzed because it reflects the changes in the functional groups of wood components after thermo-vacuum treatment. As can be observed from Fig. 3, there was a decrease in the intensity of the absorbance at $1738 \mathrm{~cm}^{-1}$, assigned to $\mathrm{C}=\mathrm{O}$ vibration of the non-conjugated acetyl or carbonyl groups in xylan [47]. This indicated that a part of acetyl groups in the wood were deacetylated during thermo-vacuum treatment. The intensity of the band at $1596 \mathrm{~cm}^{-1}$, assigned to the aromatic skeletal vibrations plus $\mathrm{C}=\mathrm{O}$ stretch of lignin $[48,49]$, showed a decrease after thermovacuum treatment, indicating that the treatment resulted in a loss of the $\mathrm{C}=\mathrm{O}$ group linked to the aromatic skeleton in lignin. This change might be due to the occurrence of a cross-linking reaction in the lignin by heat treatment [50]. The slight increase of the intensity in the band at $1508 \mathrm{~cm}^{-1}$, assigned to the stretching vibrations of the $\mathrm{C}=\mathrm{C}$ bonds of aromatic skeletal in lignin, suggested that the amorphous carbohydrates (especially hemicelluloses) degraded and that the relative amount of lignin in the samples increased as treatment temperature rose. A gradual shift in this band was observed from 1508 to $1512 \mathrm{~cm}^{-1}$ with the increase of treatment temperature, suggesting the splitting of aliphatic side chains and cleavage of $\beta-O-4$ linkages in the lignin structure, followed by condensation reactions [51, 52]. The intensity of the peak at $1373 \mathrm{~cm}^{-1}$, assigned to the $\mathrm{C}-\mathrm{H}$ bending vibrations in cellulose and hemicelluloses [50, 53], varied slightly after treatment. Similar results have been reported for bamboo and Gympie messmate wood [35, 54]. The decrease in the intensity of the band at $1230 \mathrm{~cm}^{-1}$, assigned to $\mathrm{C}-\mathrm{O}$ stretching vibrations in lignin and acetyl and carboxylic vibrations in xylan, indicated that the formation of condensed structures in lignin and the occurrence of deacetylation in hemicelluloses [53]. The increase in the intensity of the band at $1058 \mathrm{~cm}^{-1}$, assigned to $\mathrm{C}-\mathrm{O}$ stretching vibrations in cellulose and hemicelluloses [42, 53], suggested the formation of aliphatic alcohols during thermo-vacuum treatment. The intensity of the band at $895 \mathrm{~cm}^{-1}$, assigned to $\beta$-glycosidic stretching of the sugars [35, 54], decreased after heat treatment. This can be due to the results of thermal degradation of hemicelluloses [35].

\section{Dynamic water vapour sorption analysis}

Wood as a hygroscopic material contains a certain percentage of water and is sensitive to the changes of environmental moisture (adsorbing water as the relative humidity increased and desorbing water as the relative humidity decreased) [55]. The moisture sorption isotherms curves of the untreated and heat treated samples are shown in Fig. 4. In this study, the characteristic sigmoidal shape sorption curves for cellulose-based materials can be observed in the untreated and heat-treated samples. As shown in Fig. 4, the equilibrium moisture content (EMC) in the untreated and heat-treated samples increased with the increasing $\mathrm{RH}$. There was a reduction in the equilibrium moisture content recorded during the adsorption and desorption process resulting from the thermo-vacuum modification of wood. The equilibrium moisture content decreased as the temperature of treatment rose. It is well known, hygroscopicity is highly related to the accessible hydroxyl groups of wood $[49,56]$. The reduction in hygroscopicity after thermovacuum treatment is probably due to the reduction of the hydrophilic groups. As indicated by the FTIR spectra in this study, the degradation of the carbonyl groups in xylan 

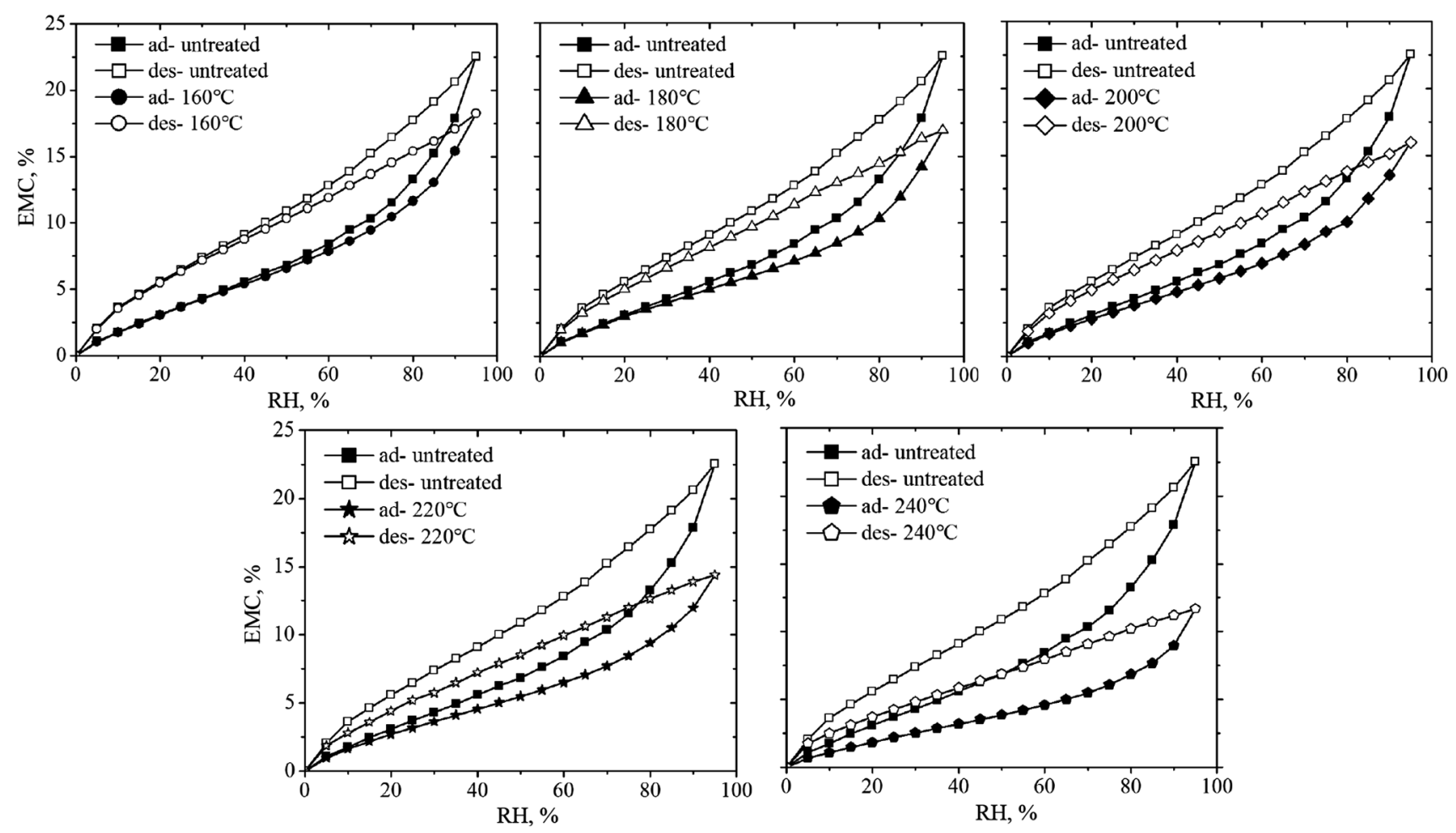

Fig. 4 Moisture sorption isotherms of untreated and heat-treated eucalypt wood

and the loss of the $\mathrm{C}=\mathrm{O}$ group linked to the aromatic skeleton in lignin could contribute to the decrease of wood hygroscopicity. According to previous studies, the number of accessible hydroxyl groups of wood was quantified by the hydrogen-deuterium exchange and ${ }^{2} \mathrm{H}$ NMR spectroscopy before and after heat treatment [57]. The results showed that there was a steady decrease in accessible hydroxyl groups as the temperature of heat treatment increased and it coincided with the decrease in hygroscopicity after heat treatment. Furthermore, after heat treatment, there may be an increase in the relative cellulose crystalline content due to the ultrastructural reorganization of cellulose from the paracrystalline (less ordered) state to the crystalline one, which effectuated a further reduction in the available sorption sites [58]. This also resulted in the decrease in hygroscopicity of wood. Due to its aromatic structure, lignin is more hydrophobic than the holocellulose fraction. Thus, the increase in the relative content of lignin may result in the decrease of wood hygroscopicity. In addition, it has been shown that the cross-linking of lignin took place during thermovacuum treatment. The cross-linking of lignin resulted in a restraining effect on cell-wall expansion, which is responsible for binding water molecules during sorption $[58,59]$.

The hysteresis is usually defined as the differences of the equilibrium moisture content values between desorption and adsorption processes at the same relative humidity. The

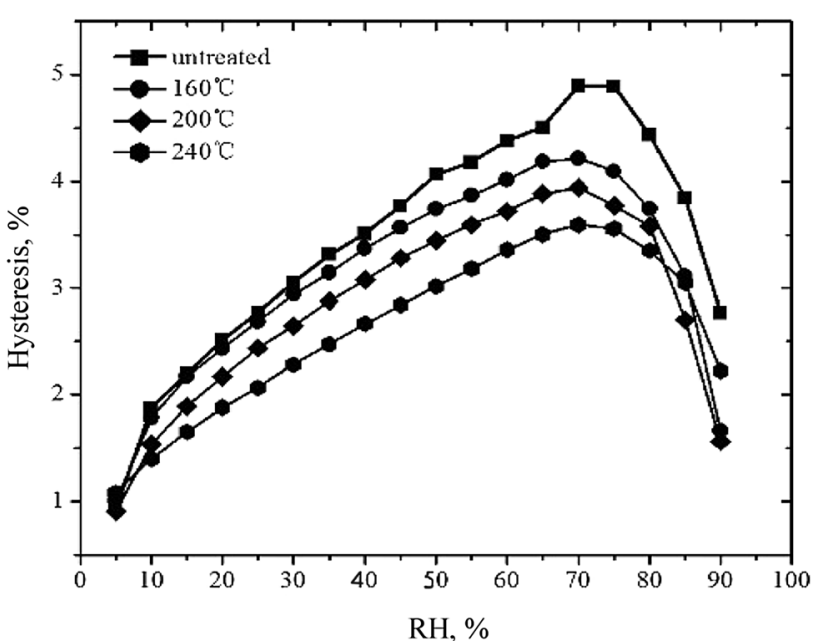

Fig. 5 Sorption hysteresis of untreated and heat-treated eucalypt wood

hysteresis of the untreated and heat-treated E. pellita wood is shown in Fig. 5. As shown in Fig. 5, in general, the hysteresis had a decreasing trend with the increasing treatment temperature. Similar results have been reported by the previous studies [50]. However, contradictory results have been obtained on the effects of heat treatment on sorption hysteresis. On the one hand, previous studies indicated that heat treatment had no effect on the sorption hysteresis of wood [60]. On the other hand, other 
researchers observed that the sorption hysteresis for poplar and beech wood increased as treatment temperature rose during heat treatment [61]. The differences in the changes of sorption hysteresis of heat-treated wood might be due to several factors such as the process parameters of treatment, the state of specimens and the treatment methods. So far, the effects of heat treatment on sorption hysteresis are still unclear. Therefore, further studies are needed to investigate the mechanism of changes in sorption hysteresis of heattreated wood.

\section{Conclusions}

Thermo-vacuum treatment led to clear changes in the chemical properties of E. pellita wood. Holocellulose and alpha-cellulose contents decreased, whereas lignin and extractives contents increased with increasing treatment temperature. The decrease in the content of hydrogen and the increase in the content of carbon indicated the loss of functional groups containing hydrogen during heat treatment. The equilibrium moisture content and sorption hysteresis of wood decreased after heat treatment. FTIR indicated a degradation of the carbonyl groups in xylan and a loss of the $\mathrm{C}=\mathrm{O}$ group linked to the aromatic skeleton in lignin. These chemical changes resulted in a decrease of the accessible moisture sorbing sites in the wood and explained the reduction of hygroscopicity in heat-treated wood.

Acknowledgements The authors would like to thank the Chinese National Natural Science Foundation for financial support of the project "Thermal effect and mechanism of wood under vacuum heat treatment", Grant No. 31370558.

\section{References}

1. Sun BL, Wang XH, Liu JL (2013) Changes in dimensional stability and mechanical properties of Eucalyptus pellita by melamine-urea-formaldehyde resin impregnation and heat treatment. Eur J Wood Prod 71:557-562

2. Zhan J, Avramidis S (2016) Needle fir wood modified by surface densification and thermal post-treatment: hygroscopicity and swelling behavior. Eur J Wood Prod 74:49-56

3. Aytin A, Korkut S, Ünsal Ö, Çakıcıer N (2015) The effects of heat treatment with the ThermoWood method on the equilibrium moisture content and dimensional stability of wild cherry wood. BioResources 10:2083-2093

4. Sini M-K, Hannu V (2009) Decay resistance of sapwood and heartwood of untreated and thermally modified Scots pine and Norway spruce compared with some other wood species. Wood Mat Sci Eng 4:105-114

5. Hakkou M, Pétrissans M, Zoulalian A, Gérardin P (2005) Investigation of wood wettability changes during heat treatment on the basis of chemical analysis. Polym Degrad Stab 89:1-5

6. Pandey KK (1999) A study of chemical structure of soft and hardwood and wood polymers by FTIR spectroscopy. J Appl Polym Sci 71:1969-1975
7. Boonstra MJ, Tjeerdsma B (2006) Chemical analysis of heat treated softwoods. Eur J Wood Prod 64:204-211

8. González-Peña MM, Curling SF, Hale MDC (2009) On the effect of heat on the chemical composition and dimensions of thermally-modified wood. Polym Degrad Stab 94:2184-2193

9. Severo ETD, Calonego FW, Sansigolo CA (2012) Physical and chemical changes in juvenile and mature woods of Pinus elliottii var. elliottii by thermal modification. Eur J Wood Prod 70:741-747

10. Tumen I, Aydemir D, Gunduz G, Uner B, Cetin H (2010) Changes in the chemical structure of thermally treated wood. BioResources 5:1936-1944

11. Brosse N, El Hage R, Chaouch M, Pétrissans M, Dumarçay S, Gérardin P (2010) Investigation of the chemical modifications of beech wood lignin during heat treatment. Polym Degrad Stab 95:1721-1726

12. Severo ETD, Calonego FW, Sansígolo CA, Bond B (2016) Changes in the chemical composition and decay resistance of thermally-modified hevea brasiliensis wood. PLoS One 11:e0151353

13. Chen Y, Gao J, Fan Y, Tshabalala MA, Stark NM (2012) Heatinduced chemical and color changes of extractive-free black locust (Robinia pseudoacacia) wood. BioResources 7:2236-2248

14. Windeisen E, Strobel C, Wegener G (2007) Chemical changes during the production of thermo-treated beech wood. Wood Sci Technol 41:523-536

15. Chen Y, Fan Y, Gao J, Li H (2012) Coloring characteristics of in situ lignin during heat treatment. Wood Sci Technol 46:33-40

16. Liu H, Shang J, Chen X, Kamke FA, Guo K (2014) The influence of thermal-hydro-mechanical processing on chemical characterization of Tsuga heterophylla. Wood Sci Technol 48:373-392

17. Nuopponen M, Vuorinen T, Jämsä S, Viitaniemi P (2003) The effects of a heat treatment on the behaviour of extractives in softwood studied by FTIR spectroscopic methods. Wood Sci Technol 37:109-115

18. Candelier K, Dumarçay S, Pétrissans A, Gérardin P, Pétrissans M (2013) Comparison of mechanical properties of heat treated beech wood cured under nitrogen or vacuum. Polym Degrad Stab 98:1762-1765

19. Wang Z, Sun B, Liu J (2016) Effect of thermo-vacuum treatment on the color and chemistry of larch wood. BioResources 11:2349-2360

20. Wang XH, Fei BH, Liu JL (2014) Effect of vacuum heat treatment temperature on physical and mechanical properties of $E u$ calyptus pellita wood. Wood Fiber Sci 46:1-8

21. Allegretti O, Brunetti M, Cuccui I, Ferrari S, Nocetti M, Terziev N (2012) Thermo-vacuum modification of spruce (Picea abies Karst.) and fir (Abies alba Mill.) wood. BioResources 7:3656-3669

22. Ferrari S, Allegretti O, Cuccui I, Moretti N, Marra M, Todaro L (2013) A revaluation of turkey oak wood (Quercus cerris L.) through combined steaming and thermo-vacuum treatments. BioResources 8:5051-5066

23. Kutnar A, Kričej B, Pavlič M, Petrič M (2013) Influence of treatment temperature on wettability of Norway spruce thermally modified in vacuum. J Adhes Sci Technol 27:963-972

24. GB/T 2677.2-1993 (1993) Fibrous raw material-determination of moisture content. General Administration of Quality Supervision, Inspection and Quarantine of the People's Republic of China, Beijing, China, pp 200-201

25. GB/T 2677.3-1993 (1993) Fibrous raw material-determination of ash. General Administration of Quality Supervision, Inspection and Quarantine of the People's Republic of China, Beijing, China, pp 202-203

26. GB/T 2677.8-1994 (1995) Fibrous raw material-determination of acid-insoluble lignin. General Administration of Quality 
Supervision, Inspection and Quarantine of the People's Republic of China, Beijing, China, pp 213-215

27. GB/T 2677.10-1995 (1996) Fibrous raw material-determination of holocellulose. General Administration of Quality Supervision, Inspection and Quarantine of the People's Republic of China, Beijing, China, pp 220-223

28. GB/T 744-1989 (1989) Pulps-determination of $\alpha$-cellulose. General Administration of Quality Supervision, Inspection and Quarantine of the People's Republic of China, Beijing, China, pp 156-158

29. GB/T 2677.6-1994 (1995) Fibrous raw material-determination of solvent extractives. General Administration of Quality Supervision, Inspection and Quarantine of the People's Republic of China, Beijing, China, pp 210-212

30. GB/T 2677.5-1993 (1993) Fibrous raw material-determination of one percent sodium hydroxide solubility. General Administration of Quality Supervision, Inspection and Quarantine of the People's Republic of China, Beijing, China, pp 207-209

31. Sun BL, Liu JL, Liu SJ, Yang Q (2011) Application of FT-NIRDR and FT-IR-ATR spectroscopy to estimate the chemical composition of bamboo (Neosinocalamus affinis Keng). Holzforschung 65:689-696

32. Wang Z, Yang X, Sun B, Chai Y, Liu J, Cao J (2016) Effect of vacuum heat treatment on the chemical composition of larch wood. BioResources 11:5743-5750

33. Zhang Y, Yu W, Zhang Y (2013) Effect of steam heating on the color and chemical properties of Neosinocalamus affinis bamboo. J Wood Chem Technol 33:235-246

34. Akguuml M (2012) The effect of heat treatment on some chemical properties and colour in Scots pine and Uludağ fir wood. Int J Phys Sci 7:2854-2859

35. Meng F, Yu Y, Zhang Y, Yu W, Gao J (2016) Surface chemical composition analysis of heat-treated bamboo. Appl Surf Sci 371:383-390

36. Boonstra MJ, Tjeerdsma B (2006) Chemical analysis of heat treated softwoods. Holz als Roh-und Werkstoff 64:204-211

37. Esteves B, Pereira H (2008) Wood modification by heat treatment: a review. BioResources 4:370-404

38. Yildiz S, Gezer ED, Yildiz UC (2006) Mechanical and chemical behavior of spruce wood modified by heat. Build Environ 41:1762-1766

39. Bartkowiak M, Zakrzewski R (2004) Thermal degradation of lignins isolated from wood. J Therm Anal Calorim 77:295-304

40. Priadi T, Hiziroglu S (2013) Characterization of heat treated wood species. Mater Des 49:575-582

41. Esteves B, Videira R, Pereira H (2011) Chemistry and ecotoxicity of heat-treated pine wood extractives. Wood Sci Technol 45:661-676

42. Herrera R, Erdocia X, Llano-Ponte R, Labidi J (2014) Characterization of hydrothermally treated wood in relation to changes on its chemical composition and physical properties. J Anal Appl Pyrol 107:256-266

43. Bobleter O, Binder H (1980) Dynamischer hydrothermaler Abbau von Holz (in German). Holzforschung 34:48-51

44. Tjeerdsma BF, Boonstra M, Pizzi A, Tekely P, Militz H (1998) Characterisation of thermally modified wood: molecular reasons for wood performance improvement. Holz als Roh-und Werkstoff $56: 149-153$

45. Kondo T (1998) Hydrogen bonds in cellulose and cellulose derivatives. polysaccharides: structural diversity and functional versatility. Marcel Dekker, New York, pp 131-172

46. Nishiyama Y, Sugiyama J, Chanzy H, Langan P (2003) Crystal structure and hydrogen bonding system in cellulose $\mathrm{I} \alpha$ from synchrotron X-ray and neutron fiber diffraction. J Am Chem Soc 125:14300-14306

47. Kotilainen RA, Toivanen TJ, Alén RJ (2000) FTIR monitoring of chemical changes in softwood during heating. J Wood Chem Technol 20:307-320

48. Faix O (1991) Classification of lignins from different botanical origins by FT-IR spectroscopy. Holzforschung 45:21-28

49. Guo J, Song K, Salmén L, Yin Y (2015) Changes of wood cell walls in response to hygro-mechanical steam treatment. Carbohyd Polym 115:207-214

50. Yin Y, Berglund L, Salmén L (2011) Effect of steam treatment on the properties of wood cell walls. Biomacromolecules 12:194-202

51. Chen Y, Fan Y, Gao J, Stark NM (2012) The effect of heat treatment on the chemical and color change of black locust (Robinia pseudoacacia) wood flour. BioResources 7:1157-1170

52. Windeisen E, Wegener G (2008) Behaviour of lignin during thermal treatments of wood. Ind Crop Prod 27:157-162

53. Li MY, Cheng SC, Li D, Wang SN, Huang AM, Sun SQ (2015) Structural characterization of steam-heat treated Tectona grandis wood analyzed by FT-IR and 2D-IR correlation spectroscopy. Chin Chem Lett 26:221-225

54. Cademartori PHG, dos Santos PSB, Serrano L, Labidi J, Gatto DA (2013) Effect of thermal treatment on physicochemical properties of Gympie messmate wood. Ind Crop Prod 45:360-366

55. Droin A, Taverdet JL, Vergnaud JM (1988) Modeling the kinetics of moisture adsorption by wood. Wood Sci Technol 22:11-20

56. Tjeerdsma BF, Militz H (2005) Chemical changes in hydrothermal treated wood: FTIR analysis of combined hydrothermal and dry heat-treated wood. Holz als Roh-und Werkstoff 63:102-111

57. Phuong LX, Takayama M, Shida S, Matsumoto Y, Aoyagi T (2007) Determination of the accessible hydroxyl groups in heattreated Styrax tonkinensis (Pierre) Craib ex Hartwich wood by hydrogen-deuterium exchange and ${ }^{2} \mathrm{H}$ NMR spectroscopy. Holzforschung 61:488-491

58. Jalaludin Z, Hill CA, Xie Y, Samsi HW, Husain H, Awang K, Curling SF (2010) Analysis of the water vapour sorption isotherms of thermally modified acacia and sesendok. Wood Mater Sci Eng 5:194-203

59. Repellin V, Guyonnet R (2005) Evaluation of heat-treated wood swelling by differential scanning calorimetry in relation to chemical composition. Holzforschung 59:28-34

60. Militz H (2002) Thermal treatment of wood: European processes and their background. International research group on wood preservation, IRG/WP 02-40241

61. Olek W, Majka J, Czajkowski $Ł$ (2013) Sorption isotherms of thermally modified wood. Holzforschung 67:183-191 